\title{
APLIKASI SISTEM INFORMASI GEOGRAFIS SPBU DI KOTA PADANG BERBASIS MOBILE
}

\author{
Nori Sahrun, Sularno, Faras Khairi Edwar \\ Prodi Manajemen Sekolah Tinggi Ilmu Ekonomi Riau. Indonesia \\ Prodi Sistem Informasi Universitas Dharma Andalas, Indonesia \\ Norisahrun84@gmail.com, Soelarno@unidha.ac.id
}

\begin{abstract}
The benefits of the gas station are not only for filling fuel for vehicles, but also can provide great benefits for the community, especially drivers or visitors to the gas station with the facilities available at the gas station. However, not all people know the location of gas stations in all areas in this part of the city of Padang, so the lack of information about the location and facilities of each gas station can make it difficult for motorists who may forget to fill up fuel before traveling or going to other areas and do not know where they are. Gas stations in the area he visited. Of the many gas stations in Padang, only a few can be remembered by the community. Maybe we can only remember gas stations that we often pass. It is expected that the building of a Geographic Information System displays the location of gas stations and the facilities of each gas station, so that users who are merely looking to find out the facilities at the gas stations can find out
\end{abstract}

Keywords: gas stations, fuel, facilities, vehicles, Geographic Information Systems

\begin{abstract}
Abstrak-Manfaat dari SPBU bukan hanya untuk mengisi BBM buat kendaraan, tetapi juga dapat memberi manfaat yang besar bagi masyarakat, khususnya pengendara atau pengunjung SPBU dengan adanya fasilitas-fasilitas yang tersedia di SPBU tersebut. Namun tidak semua masyarakat mengetahui informasi lokasi SPBU di semua daerah dibagian kota Padang ini, sehingga kurangnya informasi tentang lokasi dan fasilitas-fasilitas dari setiap SPBU tersebut bisa mempersulit pengendara yang mungkin lupa untuk mengisi BBM sebelum berpergian atau pergi ke daerah lain dan tidak mengetahui dimana adanya SPBU di daerah yang dia kunjungi. Dari sekian banyak SPBU di Padang hanya beberapa yang dapat diingat oleh masyarakat. Mungkin kita hanya bisa meningat SPBU yang sering kita lewati.Diharapkan dengan dibangunya sebuah Sistem Informasi Geografis ini menampilkan lokasi SPBU dan fasilitas dari masingmasing SPBU, sehingga bagi pengguna yang hanya sekedar untuk mencari tahu fasilitas yang ada pada SPBU dapat mengetahui
\end{abstract}

Kata kunci: spbu,bbm,fasilitas,kendaraan, Sistem Informasi Geografis

\section{PENDAHULUAN}

Sistem Informasi Geografis (SIG) merupakan suatu sistem informasi berbasiskan komputer untuk menyimpan, mengelola dan menganalisis, serta memanggil data bereferensi geografis yang berkembang pesat pada lima tahun terakhir ini. Manfaat dari SIG adalah memberikan kemudahan kepada para pengguna atau para pengambil keputusan untuk menentukan kebijaksanaan yang akan diambil, khususnya yang berkaitan dengan aspek keruangan (spasial).

Sistem informasi geografis sendiri telah dikemukan oleh beberapa penulis. Menurut Prasetyo Hary Daniel (2003) yang dikutip oleh Shindy, Bambang, Arief. (2015) dalam Jurnal Geodesi Undip, vol 4, hal 20 bahwa Sistem Informasi Geografis (SIG) adalah suatu sistem yang mengcapture, mengecek, mengintegrasikan, memanipulasi, menganalisa, menganalisa, dan menampilkan data secara spatial (keruangan) atau merepresentasikan operasi-operasi umum database, seperti query dan analisa statitstik, dengan kemampuan visualisasi dan analisa yang unik yang dimiliki oleh pemetaan. Kemapuan inilah yang membedakan SIG dengan Sistem Informasi lainnya yang 
membuatnya menjadi berguna untuk berbagai kalangan untuk menjelaskan kejadian, merencanakan strategi, dan memprediksi apa yang akan terjadi.

Penelitian tentang sistem informasi geografis telah dilakukan sebelumnya oleh Koko Mukti Wibowo, Indra Kanedi, Juju Jumadi (2015) dalam jurnal yang berjudul "Sistem informasi geografis menentukan lokasi pertambangan batu bara di provinsi bengkulu berbasis website" dan Adytama Annugerah, Indah Fitri Astuti, Awang Harsa Kridalaksana (2016) dalam jurnal yang berjudul "Sistem informasi geografis berbasis web pemetaan lokasi toko oleh-oleh khas samarinda"

Kemampuan dasar dari SIG adalah mengintegrasikan berbagai operasi basis data seperti query, menganalisisnya serta menampilkannya dalam bentuk pemetaanberdasarkan letak geografisnya (Prahasta, 2002).

SPBU ( Stasiun Pengisian Bahan bakar Umum ) merupakan prasarana yang disediakan oleh PT. Pertamina untuk masyarakat luas untuk memenuhi kebutuhan bahan bakar, SPBU adalah fasilitas yang sangat penting dalam kehidupan dan aktifitas seharihari. Oleh karna itu, informasi mengenai keberadaan SPBU sangat diperlukan bagi lapisan masyarakat luas.

Penyampaian informasi tentang akses menuju lokasi SPBU tersebut hanya menggunakan metode dari mulut ke mulut atau diakses dari Google Map. Akan lebih baik jika ada cara yang membantu masyarakat mengetahui lokasi dan informasi dari SPBU tersebut. Dalam masalah ini, perlu adanya suatu sistem untuk menangani permasalahan tersebut agar berguna dan lebih efisien dengan memanfaatkan teknologi informasi yang semakin canggih saat ini.

\section{METODEDAN DATA}

Dalam penelitian ini, peneliti mengunakan metode deskriptif yaitu dengan mengumpulkan data dan informasi lokasi SPBU di kota padang. Dalam pengambilan data peneliti melakukan dengan cara observasi secara langsung dengan para masyarakat padang. Alat analisis yang digunakan adalah $U M L$ (bagan alir) merupakan representasi secara grafik dari satu algoritma atau prosedur untuk menyelesaikan suatu masalah. Implementasi program menggunakan bahasa pemrograman PHP dengan database MySQL.

Stasiun Pengisian Bahan Bakar Umum (SPBU) merupakan prasarana umum yang disediakan oleh PT. Pertamina untuk masyarakat luas guna memenuhi kebutuhan bahan bakar. Pada umumnya SPBU menyediakan berbagai jenis bahan bakar diantaranya adalah premium, solar, pertamax, dan pertamax plus. Daftar SPBU yang ada di Kota Padang dapat dilihat pada Tabel 1.1.

Tabel 1.1Daftar Lokasi SPBU di Kota Padang

\begin{tabular}{|c|c|c|c|c|}
\hline No & Nama SPBU & Alamat & Latitude & Longitude \\
\hline 1. & SPBU Gunung Pangilun & $\begin{array}{l}\text { Jl. Gajah Mada, Gn. } \\
\text { Pangilun, Nanggalo }\end{array}$ & -0.9061398 & 100.3612577 \\
\hline 2. & SPBU Khatib Sulaiman & $\begin{array}{l}\text { Jl. Khatib Sulaiman, Ulak } \\
\text { Karang Selatan }\end{array}$ & -0.9108998 & 100.3539001 \\
\hline 3. & SPBU Wowo & $\begin{array}{llr}\text { JL S. } & \text { Parman, } & \text { Ulak } \\
\text { Karang, } & \text { Ulak } & \text { Karang } \\
\text { Selatan } & & \\
\end{array}$ & -0.9037348 & 100.3486224 \\
\hline 4. & SPBU Tabing & $\begin{array}{ll}\text { Jalan Profesor } & \text { Doktor } \\
\text { Hamka,Parupuk } & \text { Tabing, } \\
\text { Koto Tangah } & \end{array}$ & -0.8897821 & 100.3496163 \\
\hline 5. & SPBU Marapalam & $\begin{array}{l}\text { J1. Dr. Sutomo, Kubu } \\
\text { Marapalam, Padang Timur }\end{array}$ & -0.9504444 & 100.3842844 \\
\hline
\end{tabular}




\begin{tabular}{|c|c|c|c|c|}
\hline 6. & SPBU Padang Baru & $\begin{array}{l}\text { Jalan Alang Lawas 2, } \\
\text { Ganting Parak Gadang, } \\
\text { Padang Selatan }\end{array}$ & -0.9263667 & 100.352253 \\
\hline 7. & SPBU Ranah Binuang & $\begin{array}{lrr}\text { Jalan } & \text { Kesatria, } & \text { Ganting } \\
\text { Parak } & \text { Gadang, } & \text { Padang } \\
\text { Timur } & & \\
\end{array}$ & -0.9498436 & 100.3703476 \\
\hline 8. & SPBU Jati & $\begin{array}{ll}\text { Jalan } & \text { Perintis } \\
\text { Kemerdekaan, Jati Baru, } \\
\text { Padang Timur }\end{array}$ & -0.9413191 & 100.3637457 \\
\hline 9. & SPBU Kalumbuk & Kalumbuk, Kuranji & -0.9128532 & 100.3947917 \\
\hline 10. & SPBU Pitameh & $\begin{array}{l}\text { Tj. Saba Pitameh Nan XX, } \\
\text { Lubuk Begalung }\end{array}$ & -0.9867194 & 100.3846436 \\
\hline 11. & SPBU S.Parman & $\begin{array}{l}\text { Jl. S. Parman, Ulak Karang } \\
\text { Utara, Padang Utara }\end{array}$ & -0.905557 & 100.3508631 \\
\hline 12. & $\begin{array}{ll}\text { SPBU } & \text { Simpang } \\
\text { Kalumpang } & \end{array}$ & $\begin{array}{l}\text { Jl. Adinegoro } \text { No.41, } \\
\text { Batang Kabung Ganting, } \\
\text { Koto Tangah }\end{array}$ & -0.8442811 & 100.3309168 \\
\hline 13. & SPBU Adinegoro & $\begin{array}{l}\text { Jl. Adinegoro, Lubuk } \\
\text { Buaya, Koto Tangah }\end{array}$ & -0.8154128 & 100.3213359 \\
\hline 14. & SPBU Veteran & Purus, Padang Barat & -0.9384117 & 100.3550375 \\
\hline 15. & SPBU Batang Arau & $\begin{array}{l}\text { Jl. Batang Arau, Berok } \\
\text { Nipah, Padang Barat }\end{array}$ & -0.965285 & 100.3578955 \\
\hline 16. & SPBU Khatib Sulaiman 2 & $\begin{array}{l}\text { Jl. Khatib Sulaiman, Ulak } \\
\text { Karang Selatan }\end{array}$ & -0.9142826 & 100.3572985 \\
\hline 17. & SPBU Ampang & $\begin{array}{l}\text { Jl. Raya Ampang No.88, } \\
\text { Lubuk Lintah, Kuranji }\end{array}$ & -0.9243245 & 100.3747973 \\
\hline 18. & SPBU Pasar Ambacang & Ps.Ambacang,Kuranji & -0.9300973 & 100.3991968 \\
\hline 19. & SPBU Pisang & Pisang, Pauh, Padang Barat & -0.9451154 & 100.3993177 \\
\hline 20. & SPBU Bandar Buat & $\begin{array}{l}\text { Jalan Raya Indarung- } \\
\text { Rimbo Datar Bandar Buat, } \\
\text { Bandar Buat, Lubuk } \\
\text { Kilangan }\end{array}$ & -0.9493191 & 100.431628 \\
\hline 21. & SPBU Adinegoro 2 & $\begin{array}{l}\text { Jl. Adinegoro No.36, Koto } \\
\text { Pulai, Koto Tangah }\end{array}$ & -0.866382 & 100.3241655 \\
\hline
\end{tabular}

\section{HASIL DAN PEMBAHASAN Analisa Sistem}

Analisa terhadap suatu sistem sangat diperlukan untuk mengetahui kegiatankegiatan yang sedang berjalan dalam suatu sistem. Tujuan mengetahui kegiatan-kegiatan tersebut adalah untuk memahami dan mengerti jalannya sistem serta hambatan-hambatan yang terdapat dalam sistem tersebut.

Pada tahap ini yang perlu dilakukan adalah analisis terhadap sistem yang sedang berjalan dan bagaimana aliran dokumen yang sedang berjalan yang akan digambarkan dalam bentuk analisis pengkodean, analisis kebutuhan fungsional, analisis kebutuhan non-fungsional dan analisis pengguna.

\section{Evaluasi Sistem yang berjalan}

Setelah dilakukan analisa, perlu adanya suatu sistem yang dapat di akses oleh seluruh pengendara baik yang dari dalam kota Padang maupun di luar kota Padang yang ingin mengisi bahan bakarnya dengan mudah dan cepat. Dalam hal ini, penulis akan mencoba membuat sebuah sistem baru menggunakan Sistem Informasi Geografis agar pengendara lebih mudah dalam perjalanannya. 


\section{Perancangan Unified Modeling Language (UML)}

Perancangan desain sistem yang akan dibangun menggunakan pemodelan Unified Modelling System ( UML ). Diagram-diagram yang digunakan use case diagram, activity diagram, class diagram dan squence diagram. Adapun perancangan UML adalah sebagai berikut:

\section{Use Case Diagram}

Diagram ini menjelaskan tentang interaksi antara user dengan aplikasi. Use case diagram merupakan urutan kegiatan yang dilakukan aktor dan sistem untuk mencapai suatu tujuan tertentu. Walaupun menjelaskan kegiatan, namun use case hanya menjelaskan apa yang dilakukan oleh aktor dan sistem, bukan bagaimana aktor dan sistem melakukan kegiatan tersebut.

Adapun interaksi antara pengguna dengan sistem terlihat pada gambar 1.1 berikut.

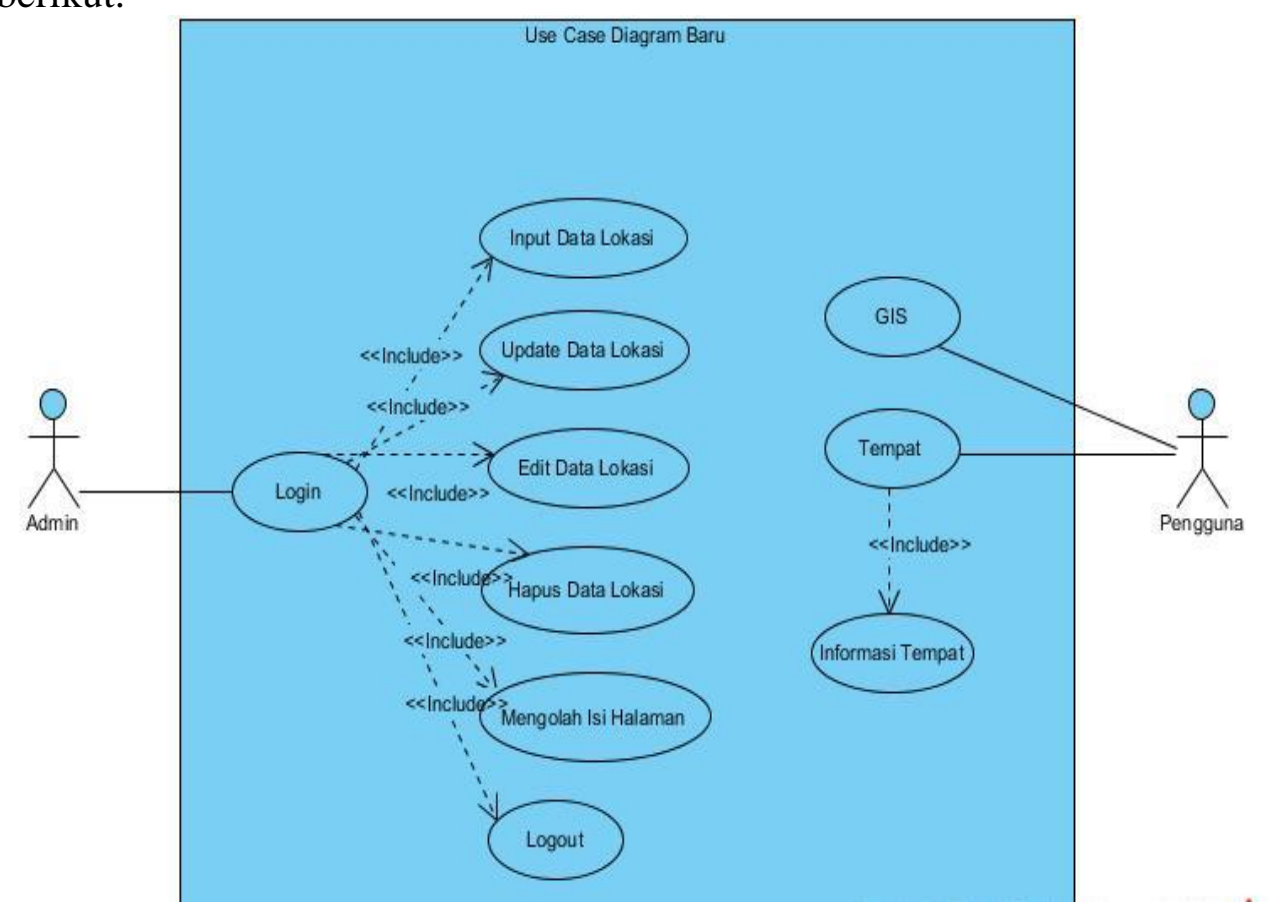

Gambar 1.1Use Case Diagram sistem baru

\section{Class Diagram}

Class diagram merupakan diagram struktural yang memodelkan sekumpulan class, interface, kolaburasi dan relasinya. Class diagram digambarkan dengan kotak. Class diagram aplikasi dijelaskan pada Gambar 1.2 


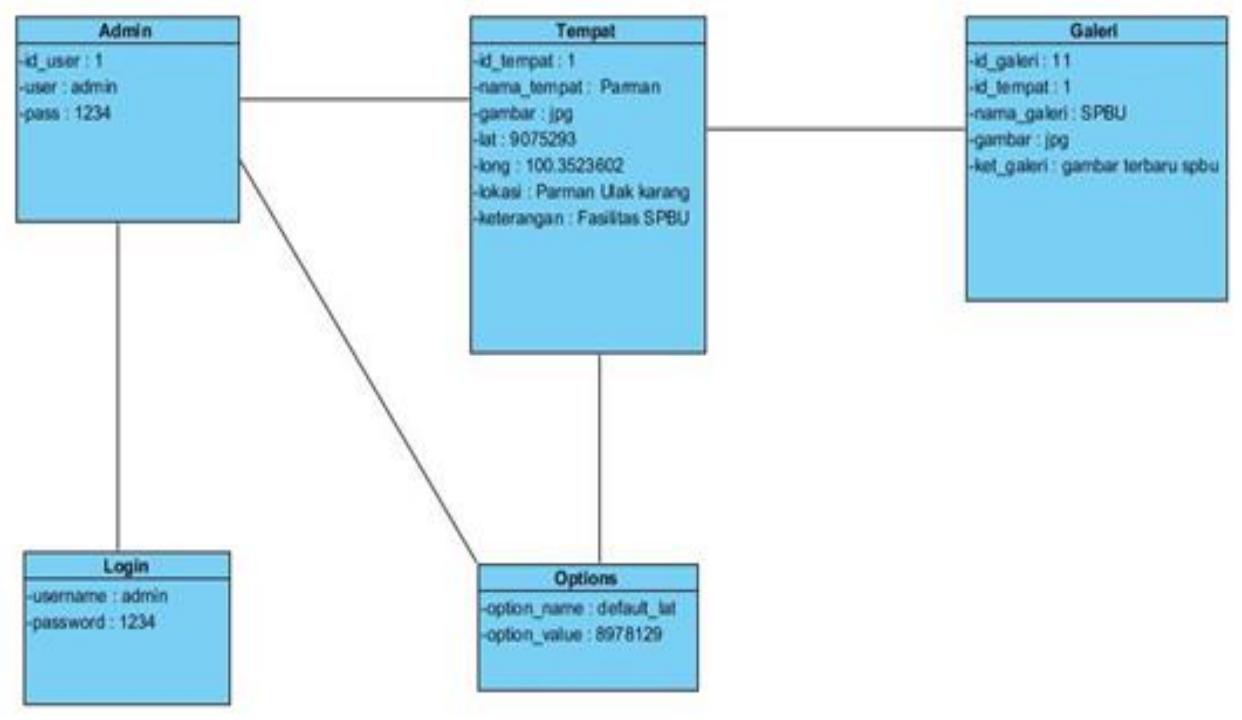

Gambar 1.2Object Diagram

3. Activity Diagram Admin

Activity Diagram pada Administrator menggambarkan bahwa Administrator melakukan login untuk dapat menambahkan data, menghapus data dan meng-update data, Activity Diagram pada Administrator bisa dilihat pada Gambar 1.3 berikut ini :

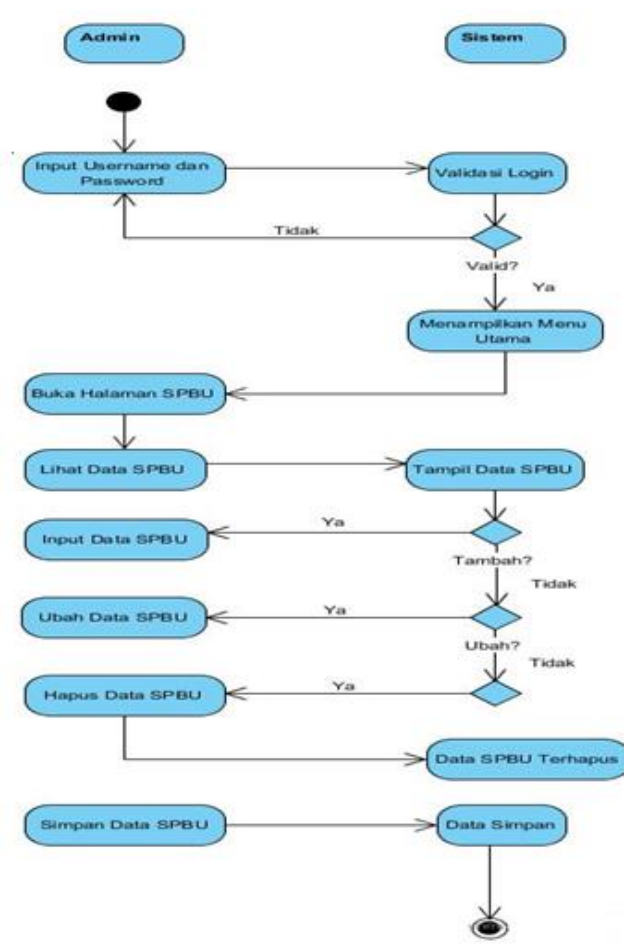

Gambar 1.3Activity Diagram Admin

4. Activity Diagram Pengguna

Activity Diagram pada Pengguna menggambarkan bahwa Pengguna hanya dapat melihat lokasi SPBU, informasi dan profile, Activity Diagram pada Pengguna bisa dilihat pada Gambar 1.4 berikut ini : 


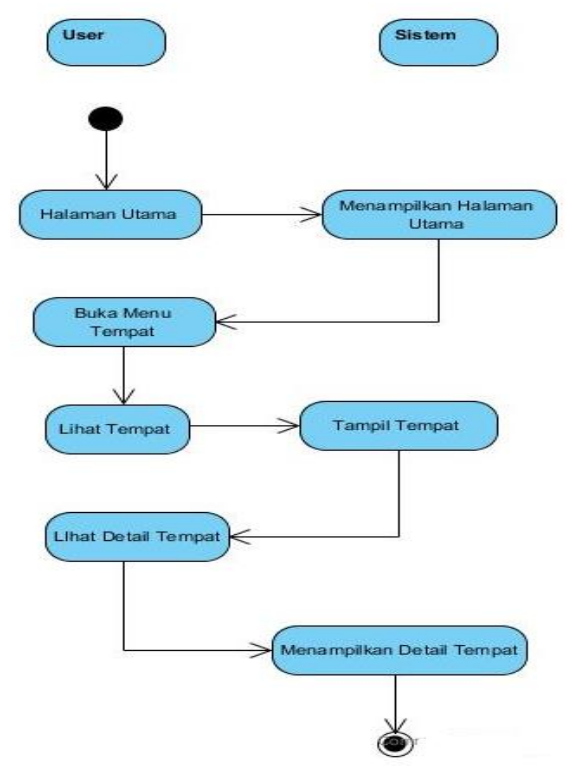

Gambar 1.4Activity Diagram Pengguna

\section{Implementasi Sistem}

Implementasi sistem merupakan bagian dari siklus pengembangan sistemuntuk melakukan sebuah implementasi maka diperlukan aplikasi yaitu perancangan interface yang sesuai dengan sistem yang dirancang ataupun yang telah dianalisa.

1. Tampilan untuk Admin

Tampilan awal saat pertama kali admin akses halaman awal. Terdapat informasi dari SPBU, seperti berita spbu, lowongan pekerjaan dan lain sebagainya

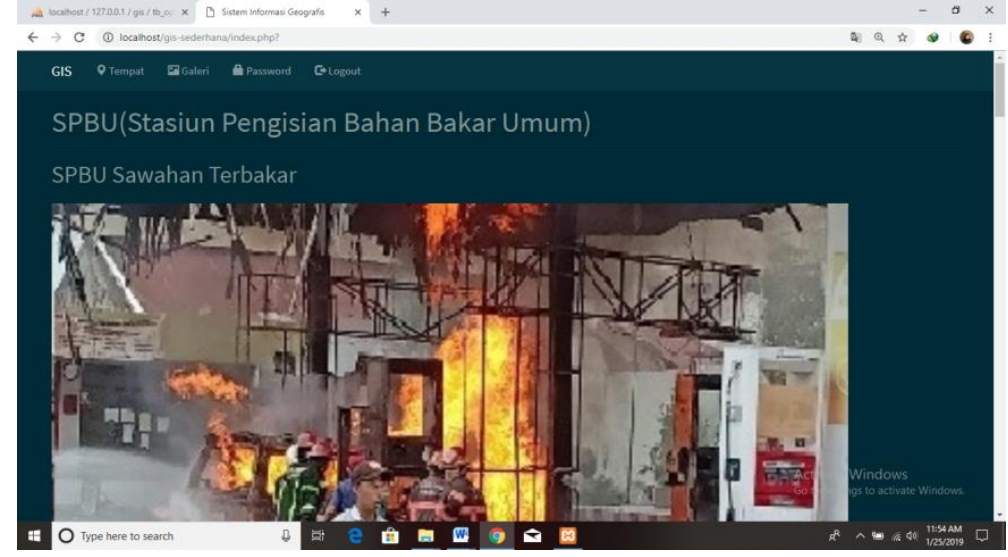

\section{Gambar 1.5Tampilan Home Admin}

2. Halaman Edit Tempat Admin

Halaman edit tempat berguna untuk memperbarui, menghapus, menambah data SPBU seperti nama spbu, alamat, latitude, longititude, gambar dan keterangan dari masing-masing spbu. 




Gambar 1.6TampilanEdit Tempat Admin

3. Halaman Tempat Pengguna

Halaman tempat menampilkan peta yang terdapat marker / titik lokasi dari masing-masing SPBU.

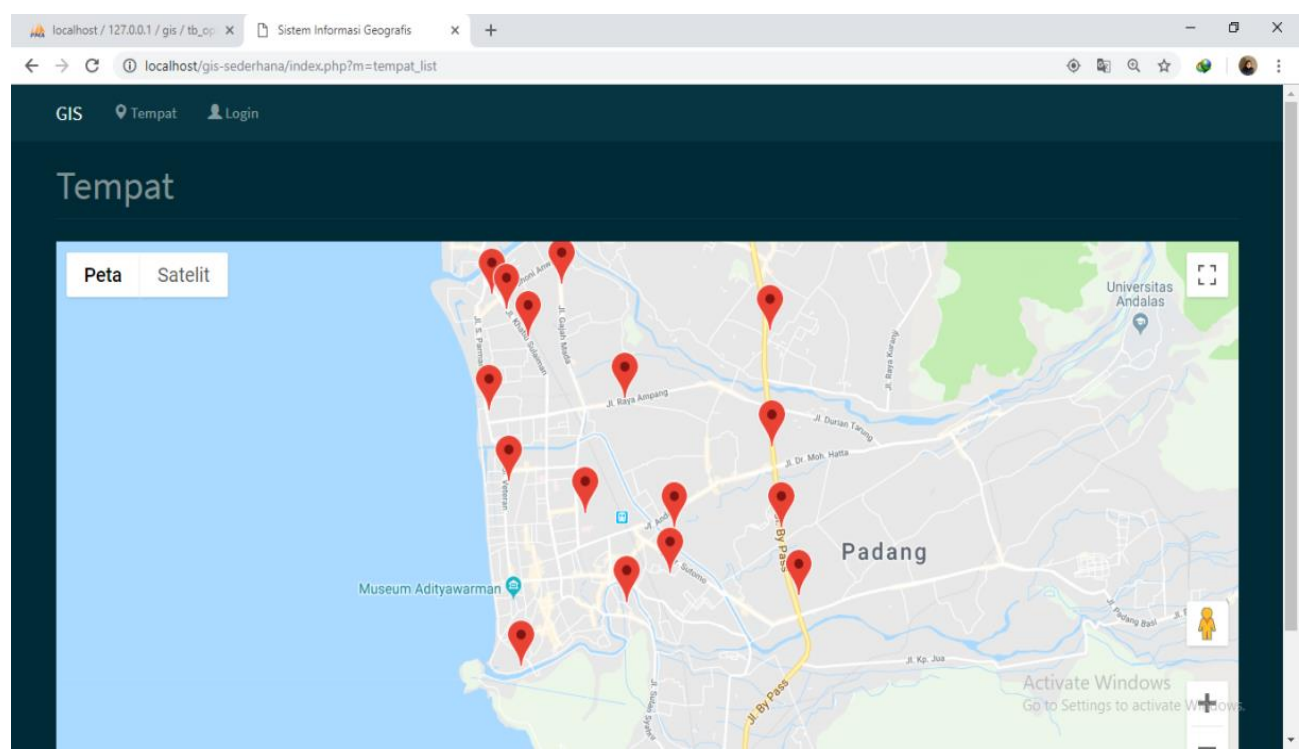

Gambar 1.7Tampilan Tempat Pengguna 
4. Halaman Detail Tempat

Detail tempat dapat di akses ketika klik marker pada halaman tempat kemudian ada tulisan detail maka dapat menampilkan fasilitas, alamat dan foto dari masing-masing SPBU.

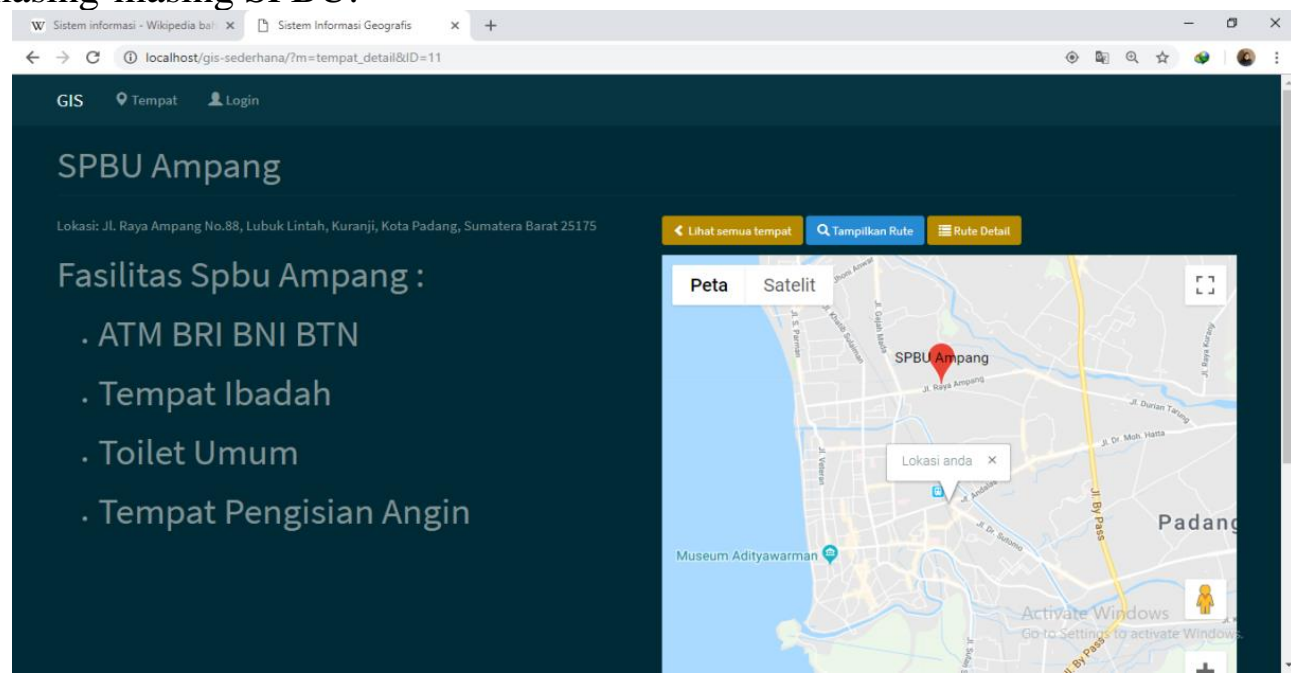

Gambar 1.7Tampilan Detail Tempat Pengguna

5. Halaman Rute Detail Tempat

Tampilan rute detail tempat berguna untuk menunjukkan rute kepada pengguna berdasarkan titik lokasi pengguna berada.

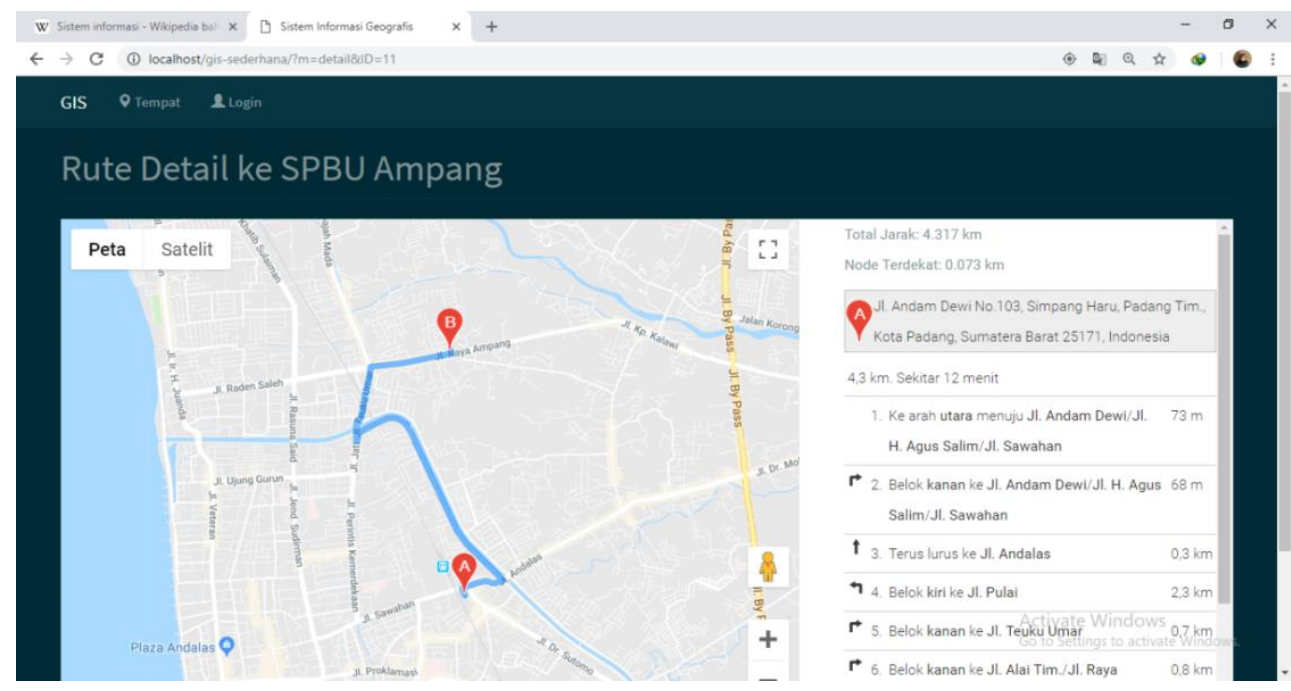

Gambar 1.8Tampilan Rute Detail Tempat Pengguna 


\section{KESIMPULAN}

Dari hasil penelitian ini dapat disimpulkan bahwa, Sistem Informasi Geografis ini menampilkan lokasi SPBU danfasilitas dari masing-masing SPBU, sehingga bagi pengguna yanghanya sekedar untuk mencari tahu fasilitas yang ada pada SPBUdapat mengetahui.Sistem ini bertujuan untuk mempermudah warga atau pendatangdari luar kota Padang dalam menemukan rute menuju SPBU yangberada pada radius sekitarnya atau yang dipilih.

\section{DAFTAR PUSTAKA}

Arahman, I. I. (2013). APLIKASI MOBILE GIS LAYANAN INFORMASI LOKASI PENTING KOTASURAKARTA BERBASIS ANDROID. Seminar Nasional Informatika 2013 (semnasIF2013) UPN "Veteran" Yogyakarta, 302-304.

Hendini , A. (2016). PEMODELAN UML SISTEM INFORMASI MONITORING PENJUALANDAN STOK BARANG (STUDI KASUS: DISTRO ZHEZHA PONTIANAK). JURNALKHATULISTIWA INFORMATIKA, VOL. IV, NO. 2, 107-111.

Kharistiani, E. (2013). SISTEM INFORMASI GEOGRAFIS PEMETAAN POTENSI SMA/SMKBERBASIS WEB (Studi Kasus : Kabupaten Kebumen) . Jurnal Sarjana TeknikInformatika Volume 1 Nomor 1, 715.

Nurdiansyah, M. (2013, May 2). SISTEM INFORMASI GEOGRAFIS UNTUK PENENTUANLOKASI SPBU BARU DI SURABAYA. Retrieved fromhttps://www.pens.ac.id/2013/05/02/20130813144934-1037/Pribadi, T. S. (2015). Simnasiptek 2015. Retrieved fromseminar.bsi.ac.id/simnasiptek/index.php/simnasiptek2015/article/download/73/73

Puspitasari , D. (2016). SISTEM INFORMASI PERPUSTAKAAN SEKOLAH BERBASIS WEB .Jurnal Pilar Nusa Mandiri Vol.XII, No.2 , 228.

Wibowo, K. M. (2015). SISTEM INFORMASI GEOGRAFIS (SIG) MENENTUKAN LOKASIPERTAMBANGAN BATU BARA DI PROVINSI BENGKULU BERBASIS WEBSITE.Jurnal Media Infotama Vol. 11 No. 1, 51-56.

Zulkarnain, S. M. (2015). PEMANFAATAN WEBGIS UNTUK PEMETAAN PERSEBARAN SPBUDI KOTA SEMARANG . Jurnal Geodesi Undip, 2021. 